\title{
Discriminating Bangladeshi Adults by Non-communicable Diseases
}

\author{
Bhuiyan Dipan ${ }^{1, *}$, Bhuyan Keshab Chandra ${ }^{2}$ \\ ${ }^{1}$ Department of Emergency, IRIS Multi-Specialty Hospital, Kolkata, India \\ ${ }^{2}$ Department of Statistics, Jahangirnagar University, Dhaka, Bangladesh
}

Email address:

dipan.bhuiyan@gmail.com (B. Dipan), kcbhuyan2002 ayahoo.com (B. K. Chandra)

${ }^{*}$ Corresponding author

To cite this article:

Bhuiyan Dipan, Bhuyan Keshab Chandra. Discriminating Bangladeshi Adults by Non-communicable Diseases. Rehabilitation Science.

Vol. 4, No. 3, 2019, pp. 35-43. doi: 10.11648/j.rs.20190403.11

Received: October 7, 2019; Accepted: October 28, 2019; Published: October 31, 2019

\begin{abstract}
In medical science, non-communicable diseases are non-infectious and non-transmissible diseases which, mainly, depend on lifestyles and socioeconomic factors and these diseases kill more people annually in low and middle income countries. Bangladesh is now a middle income country and half of annual mortality and almost half of the burden of diseases in Bangladesh are for NCDs. In this paper, attempt was made to identify the factors responsible for different types of NCDs among Bangladeshi adults. For the purpose, 808 adults were investigated and observed that 49.6 percent of them were suffering from one or more of the NCDs and 27.7 percent were exclusively suffering from diabetes. But percentage of diabetic adults was 40.7 as another 13.0 percent were suffering from multiple diseases including diabetes. A big group of (42.9\%) diabetic patients were overweight and obese and 45.3 percent were physically inactive and they were involved in sedentary activities. The important factors which discriminated adults of different diseases were age, marital status, body mass index, occupation, smoking habit, utilization of time, habit of taking restaurant and can food. This fact was detected by discriminant analysis.
\end{abstract}

Keywords: Prevalence of NCDs, Socioeconomic Factors, Risk Ratio, Discriminant Analysis

\section{Introduction}

A non-communicable disease is one which is not transmissible directly from one person to another and this disease is non-infectious. The disease includes Parkinson's disease, autoimmune diseases, strokes, most heart diseases, most cancers, diabetes, chronic kidney disease, osteoarthritis, osteoporosis, Alzheimer's disease, cataracts, and others. These diseases are classified into 4 groups, viz. (i) cardiovascular diseases (like heart attack and stroke), (ii) cancer, (iii) chronic respiratory diseases (such as chronic obstructed pulmonary disease and asthma), and (iv) diabetes. The diseases are referred to lifestyle diseases, because the maximum of these diseases are preventable illness. The most common causes for NCDs include tobacco use, alcohol abuse, poor diets (high consumption of sugar, salt, saturated fats, and trans fatty acids) and physical inactivity [1].

The sources of NCDS indicate that these diseases are associated with economic development and thus these are the diseases of the rich'. Currently NCDs kill 41 million [2] people annually and this amount is equivalent to 71 percent of all deaths in a year. Each year, 15 million die from NCDs between the ages 30 to 69 years; over 85 percent of these premature deaths occur in low and middle income countries [2]. Cardiovascular disease account for most deaths or 17.9 million people die annually, followed by cancers (9.0 million), respiratory diseases (3.9 million) and diabetes (1.6 million). In the next decade, the death will be risen by $17-$ $24 \%$ [3] and it will affect hardest in the developing world. If the present growth trend rates are prevailed, by 2020 , NCDs will attribute to 7 out of 10 deaths in developing countries, killing 52 million people annually worldwide by 2030 . The burden of disease attributed to NCDs was estimated at 85 percent in industrialized nations, 70 percent in middle income nations [3].

Bangladesh is now a middle income country and major causes of death in Bangladesh gradually shifted from acute 
infectious and parasitic diseases to NCDs [4]. The estimate in 2006 indicated that 68 percent of total deaths attributed to NCDs as against only 11 percent of total deaths due to communicable diseases [5].

The key diseases of NCDs are cancer, cardiovascular disease and chronic kidney disease (CKD). But CKD is a contributing factor to the incidence and outcomes of at least three of the diseases targeted by WHO [6]. These three diseases are diabetes, hypertension and cardiovascular disease. Chronic respiratory disease (CRD) are asthma, chronic obstructive pulmonary disease, occupational lunge disease, and pulmonary hypertension [7]. The main risk factors for developing CRDs are tobacco smoking, indoor and outdoor air pollution, allergens and occupational risks [8]. A household survey in Bangladesh estimated that tobacco-related illness was responsible for 16 percent of all deaths in the country [9].

In a separate study, it was observed that most of the Bangladeshi urban adults (36.3\%) were suffering from diabetes [4]. Very few were suffering from heart disease $(3.1 \%)$ and hypertension $(0.6 \%)$. The prevalence of diabetes in adults (20-79 years of age) was 7.4 percent in Bangladesh $[10,11]$. According to International Diabetes Federation the prevalence will be 13 percent by $2030[12,13]$.

The earlier studies indicated that the major health hazard among adults was diabetes $[14,15]$. The present study was an attempt to classify the adults by their type of NCDs, if it was prevailed, and to identify the socioeconomic factors responsible for those type of diseases. The specific objectives were

(i) to estimate the proportions of diabetic patients, heart patients, diabetic and heart patients, diabetic and kidney patients and the patients of other NCDs,

(ii) to discriminate the above group of patients and to detect the factors for discrimination.

\section{Methodology}

The present analysis was based on data collected from 808 adults of Bangladesh who were investigated by some doctors and nurses from their working places according to their convenience. The data were collected during academic session 2016-2017 when the investigators were continuing their academic carrier as M. Phil students. The investigators were instructed to collect information from the persons of ages 18 years and above. The data were recorded through a pre-designed and pre-tested printed questionnaire. The collected information from all the investigated adults were related to different socioeconomic variables including family income. Some of the variables were qualitative in nature. But for analytical purpose all the variables were noted in nominal scores.

In some studies, both in home and abroad, it was noted that NCDs were associated with body mass index (BMI) [14, 16-21]. The body mass index was measured by weight in $\mathrm{kg} /$ height in $(\mathrm{m})^{2}$ [22]. The adults were classified as underweight $[\mathrm{BMI}<20$ ], normal weight $[\mathrm{BMI}=20-<25]$, overweight $[\mathrm{BMI}=25-<30]$ and obese [BMI $>30][1]$. The association of level of obesity with the levels of NCDs was investigated by Chi-square test. The association of NCDs with each of the socioeconomic variables was also investigated by the same test, where significant association was decided when $\mathrm{P}\left(x^{2}\right) \leq 0.05$. In all cases the coefficient of association was calculated and in some cases the odd ratio and risk ratio were given to identify the adult groups who were at high risk of NCDs.

After investigation, it was noted that 49.6 percent adults were suffering from at least one of the non-communicable diseases. Among this group 27.7 percent were suffering from diabetes, 4.2 percent had heart problem, 6.9 percent were suffering from diabetes and heart problem and 6.1 percent had the problems of diabetes, hypertension and heart, and the remaining 4.7 percent were suffering from diseases other than the aforesaid non-communicable diseases (NCDs). Discriminant analysis was done to discriminate these 6 groups of adults according to prevalence of different diseases and to identify the responsible variables for discrimination.

\section{Results}

It was already mentioned that 27.7 percent adults were suffering from only diabetes. But total diabetic patients were 40.7 percent as 13 percent were suffering from other diseases except diabetes. Among the diabetic patients 83.9 percent were urban adults as against 75.2 percent urban adults in the sample (Table 1) Among the urban adults 46.4 percent were free of any disease. This percentage among rural adults was 62.5. The percentage of respondents having heart problem was 4.2 and 73.5 percent of them were urban residents. Compared to rural adults more urban adults were suffering from different types of NCDs. The differentials in proportions of prevalence of NCDs according to residential origin were significant $\left[x^{2}=28.68, p\right.$-value $\left.=0.000\right]$ The coefficient association between residence and prevalence of different NCDs was 0.188 . The odd ratio [O.R. $=1.92]$ and risk ratio $[R . R=1.43]$ ratio indicated that urban adults had more chance to be affected by NCDs.

Among the investigated adults 69.7 percent were males and 25.9 percent of them were diabetic patients. Another 12.3 percent of them were suffering from diabetes, heart and kidney at the same time. The corresponding percentages among females were less except the female patients of diabetes and kidney. However, there was no significant differences in the prevalence of different types of NCDs among males and females $\left[x^{2}=10.835, \mathrm{p}\right.$-value $\left.=0.055\right]$. The risk ratio $[R \cdot R=0.87$ indicated that male and female adults had almost similar risk of prevalence of NCDs. Similar risk was [R.R $=0.94]$ observed for both Muslim and non-Muslim adults in respect of prevalence of NCDs. In the sample 89.9 percent were Muslims and 28.4 percent of them were only diabetic patients. The corresponding percentage among non-Muslim adults was 22.0. However, this difference was not statistically significant as $\left[x^{2}=7.91\right.$, pvalue $=0.161]$. 
Among the investigated units 51.1 percent were married during the investigation period and 48.9 percent were single. More married persons (46.1\%) were either diabetic patients or they were suffering from heart and kidney problem including diabetes. The corresponding figure for non-Muslim adults was 35.2. Significant difference in prevalence rates of NCDs among married and single adults was noted $\left[x^{2}=\right.$ 65.487, p-value $=0.000]$. The coefficient of association between marital sttus and prevalence of NCDs was 0.274. The married adults were around two and half times more exposed to NCDs compared to single adults [O.R $=2.49$ ]. The married persons were at more risk by 40 percent [R.R $=$ $1.40]$.

The total investigated adults were classified into 5 classes according to their age. One group was of age less than 20 years and they were 4.5 percent. But 30.6 percent of them were suffering only from diabetes. This was the second highest group in percentage who were suffering from diabetes only. The highest group of diabetic patients was among the adults of ages 50 years and above and they were 31.7 percent in the sample. Majority $(38.6 \%)$ of the investigated units were of ages 20 years to less than 30 years. Diabetes along with heart and kidney problem were prevailed among 37.2 percent of them. The differential proportions of adults according to different age groups and different types of NCDs were significant $\left[x^{2}=78.189\right.$, pvalue $=0.000]$. The adults of old age were around 2.61 time $[$ O.R. $=2.61]$ more exposed to prevalence of different NCDs. Their risk $(\mathrm{R} . \mathrm{R}=1.55)$ for prevalence of NCDs was 55 percent more than the risk of adults of other ages. The coefficient of association between age groups and types of NCDs was 0.297.

Table 1. Distribution of adults by different socioeconomic variables and different types of non-communicable disease.

\begin{tabular}{|c|c|c|c|c|c|c|c|c|}
\hline \multirow{2}{*}{\multicolumn{2}{|c|}{ Socioeconomic variables }} & \multicolumn{6}{|c|}{ Prevalence of non-communicable diseases } & \multirow[b]{2}{*}{ Total } \\
\hline & & \multirow[t]{2}{*}{ None } & \multirow[t]{2}{*}{ Diabetes } & \multirow[t]{2}{*}{ Problem of heart } & \multirow[t]{2}{*}{$\begin{array}{l}\text { Diabetes and heart } \\
\text { problem }\end{array}$} & \multirow[t]{2}{*}{$\begin{array}{l}\text { Diabetes and kidney } \\
\text { problem }\end{array}$} & \multirow[t]{2}{*}{ Others } & \\
\hline \multicolumn{3}{|l|}{ Residence } & & & & & & \\
\hline \multirow{2}{*}{ Rural } & $\mathrm{n}$ & 125 & 32 & 10 & 9 & 12 & 12 & 200 \\
\hline & $\%$ & 62.5 & 16.0 & 5.0 & 4.5 & 6.0 & 6.0 & 24.8 \\
\hline \multirow{2}{*}{ Urban } & $\mathrm{n}$ & 282 & 192 & 24 & 47 & 37 & 26 & 608 \\
\hline & $\%$ & 46.4 & 31.6 & 3.9 & 7.7 & 6.1 & 4.3 & 75.2 \\
\hline \multicolumn{9}{|l|}{ Gender } \\
\hline \multirow{2}{*}{ Male } & $\mathrm{n}$ & 296 & 146 & 22 & 32 & 37 & 30 & 563 \\
\hline & $\%$ & 52.6 & 25.9 & 3.9 & 5.7 & 6.6 & 5.3 & 69.7 \\
\hline \multirow{2}{*}{ Female } & $\mathrm{n}$ & 111 & 78 & 12 & 24 & 12 & 8 & 245 \\
\hline & $\%$ & 45.3 & 31.8 & 4.9 & 9.8 & 4.9 & 3.3 & 30.3 \\
\hline \multicolumn{9}{|l|}{ Religion } \\
\hline \multirow{2}{*}{ Muslim } & $\mathrm{n}$ & 368 & 206 & 30 & 51 & 40 & 31 & 726 \\
\hline & $\%$ & 50.7 & 28.4 & 4.1 & 7.0 & 5.5 & 4.3 & 89.9 \\
\hline \multirow{2}{*}{ Non-Muslim } & $\mathrm{n}$ & 39 & 18 & 4 & 5 & 9 & 7 & 82 \\
\hline & $\%$ & 47.6 & 22.0 & 4.9 & 6.1 & 11.0 & 8.5 & 10.1 \\
\hline \multicolumn{9}{|l|}{ Age in years } \\
\hline \multirow{2}{*}{$<20$} & $\mathrm{n}$ & 17 & 11 & 0 & 3 & 3 & 2 & 36 \\
\hline & $\%$ & 47.2 & 30.6 & 0.0 & 8.3 & 8.3 & 5.6 & 4.5 \\
\hline \multirow{2}{*}{$20-30$} & $\mathrm{n}$ & 187 & 81 & 1 & 16 & 19 & 8 & 312 \\
\hline & $\%$ & 59.9 & 26.0 & 0.3 & 5.1 & 6.1 & 2.6 & 38.6 \\
\hline \multirow{2}{*}{$30-40$} & $\mathrm{n}$ & 45 & 9 & 2 & 2 & 2 & 6 & 66 \\
\hline & $\%$ & 68.2 & 13.6 & 3.0 & 3.0 & 3.0 & 9.1 & 8.2 \\
\hline \multirow{2}{*}{$40-50$} & $\mathrm{n}$ & 70 & 35 & 11 & 6 & 10 & 6 & 138 \\
\hline & $\%$ & 50.7 & 25.4 & 8.0 & 4.3 & 7.2 & 4.3 & 17.1 \\
\hline \multirow{2}{*}{50 and above } & $\mathrm{n}$ & 88 & 88 & 20 & 29 & 15 & 16 & 256 \\
\hline & $\%$ & 34.4 & 34.4 & 7.8 & 11.3 & 5.9 & 6.3 & 31.7 \\
\hline \multicolumn{9}{|l|}{ Marital Status } \\
\hline Currently married & $\mathrm{n}$ & 164 & 132 & 31 & 33 & 25 & 28 & 413 \\
\hline currenty married & $\%$ & 39.9 & 32.0 & 7.5 & 8.0 & 6.1 & 6.8 & 51.1 \\
\hline & $\mathrm{n}$ & 243 & 92 & 3 & 23 & 24 & 10 & 395 \\
\hline Currentiy singie & $\%$ & 61.5 & 23.3 & 0.8 & 5.8 & 6.1 & 2.5 & 48.9 \\
\hline Smoking habit & & & & & & & & \\
\hline Yes & $\mathrm{n}$ & 70 & 31 & 10 & 8 & 10 & 13 & 142 \\
\hline 105 & $\%$ & 49.3 & 21.8 & 7.0 & 5.6 & 7.0 & 9.2 & 17.6 \\
\hline No & $\mathrm{n}$ & 337 & 193 & 24 & 48 & 39 & 25 & 666 \\
\hline 100 & $\%$ & 50.6 & 29.0 & 3.6 & 7.2 & 5.9 & 3.8 & 82.4 \\
\hline Total & $\mathrm{n}$ & 407 & 224 & 34 & 56 & 49 & 38 & 808 \\
\hline Iotal & $\%$ & 50.4 & 27.7 & 4.2 & 6.9 & 6.1 & 4.7 & 100.0 \\
\hline
\end{tabular}




\begin{tabular}{|c|c|c|c|c|c|c|c|c|}
\hline \multirow{2}{*}{\multicolumn{2}{|c|}{ Socioeconomic variables }} & \multicolumn{6}{|c|}{ Prevalence of non-communicable diseases } & \multirow[b]{2}{*}{ Total } \\
\hline & & None & Diabetes & Problem of heart & $\begin{array}{l}\text { Diabetes and heart } \\
\text { problem }\end{array}$ & $\begin{array}{l}\text { Diabetes and kidney } \\
\text { problem }\end{array}$ & Others & \\
\hline \multicolumn{9}{|l|}{ Education } \\
\hline \multirow{2}{*}{ Illiterate } & $\mathrm{n}$ & 7 & 9 & 3 & 1 & 1 & 1 & 22 \\
\hline & $\%$ & 31.8 & 40.9 & 13.6 & 4.5 & 4.5 & 4.5 & 2.7 \\
\hline \multirow{2}{*}{ Primary } & $\mathrm{n}$ & 21 & 21 & 2 & 2 & 4 & 6 & 56 \\
\hline & $\%$ & 37.5 & 37.5 & 3.6 & 3.6 & 7.1 & 10.7 & 6.9 \\
\hline \multirow{2}{*}{ Secondary } & $\mathrm{n}$ & 52 & 34 & 8 & 15 & 9 & 11 & 129 \\
\hline & $\%$ & 40.3 & 26.4 & 6.2 & 11.6 & 7.0 & 8.5 & 16.0 \\
\hline \multirow{2}{*}{ Graduate and above } & $\mathrm{n}$ & 327 & 160 & 21 & 38 & 35 & 20 & 601 \\
\hline & $\%$ & 54.4 & 26.6 & 3.5 & 6.3 & 5.8 & 3.3 & 74.4 \\
\hline \multicolumn{9}{|l|}{ Occupation } \\
\hline \multirow{2}{*}{$\begin{array}{l}\text { Agriculture and } \\
\text { unskilled labor }\end{array}$} & $\mathrm{n}$ & 15 & 3 & 2 & 0 & 6 & 9 & 35 \\
\hline & $\%$ & 42.9 & 8.6 & 5.7 & 0.0 & 17.1 & 25.7 & 4.3 \\
\hline \multirow{2}{*}{$\begin{array}{l}\text { Business and skilled } \\
\text { labor }\end{array}$} & d $n$ & 31 & 26 & 9 & 4 & 4 & 2 & 76 \\
\hline & $\%$ & 40.8 & 34.2 & 11.8 & 5.3 & 5.3 & 2.6 & 9.4 \\
\hline \multirow{2}{*}{ Service } & $\mathrm{n}$ & 101 & 44 & 8 & 13 & 7 & 10 & 183 \\
\hline & $\%$ & 55.2 & 24.0 & 4.4 & 7.1 & 3.8 & 5.5 & 22.6 \\
\hline \multirow{2}{*}{$\begin{array}{l}\text { Housewife, student } \\
\text { and Others } \\
\text { Income (in } 000 \text { Taka) }\end{array}$} & $\mathrm{t} n$ & 260 & 151 & 15 & 39 & 32 & 17 & 514 \\
\hline & ка) & 50.6 & 29.4 & 2.9 & 7.6 & 6.2 & 3.3 & 63.6 \\
\hline$<30$ & $\mathrm{n}$ & 96 & 36 & 7 & 9 & 7 & 4 & 159 \\
\hline$<30$ & $\%$ & 60.4 & 22.6 & 4.4 & 5.7 & 4.4 & 2.5 & 19.7 \\
\hline 2060 & $\mathrm{n}$ & 55 & 33 & 9 & 8 & 5 & 6 & 116 \\
\hline $30-60$ & $\%$ & 47.4 & 28.4 & 7.8 & 6.9 & 4.3 & 5.2 & 14.4 \\
\hline $60-90$ & $\mathrm{n}$ & 23 & 21 & 7 & 2 & 4 & 5 & 62 \\
\hline & $\%$ & 37.1 & 33.9 & 11.3 & 3.2 & 6.5 & 8.1 & 7.7 \\
\hline $00^{+}$ & $\mathrm{n}$ & 233 & 134 & 11 & 37 & 33 & 23 & 471 \\
\hline 90 & $\%$ & 49.5 & 28.5 & 2.3 & 7.9 & 7.0 & 4.9 & 58.3 \\
\hline Tatol & $\mathrm{n}$ & 407 & 224 & 34 & 56 & 49 & 38 & 808 \\
\hline I0tal & $\%$ & 50.4 & 27.7 & 4.2 & 6.9 & 6.1 & 4.7 & 100.0 \\
\hline & & Prevale & of non-com & nicable diseases & & & & \\
\hline Socioeconomic var & ariables & None & Diabetes & Problem of heart & $\begin{array}{l}\text { Diabetes and heart } \\
\text { problem }\end{array}$ & $\begin{array}{l}\text { Diabetes and kidney } \\
\text { problem }\end{array}$ & Others & Total \\
\hline Level of obesity & & & & & & & & \\
\hline Underweight & $\mathrm{n}$ & 73 & 23 & 1 & 2 & 5 & 3 & 107 \\
\hline & $\%$ & 68.2 & 21.5 & 0.9 & 1.9 & 4.7 & 2.8 & 13.2 \\
\hline Normol & $\mathrm{n}$ & 211 & 108 & 16 & 27 & 25 & 18 & 405 \\
\hline Normal & $\%$ & 52.1 & 26.7 & 4.0 & 6.7 & 6.2 & 4.4 & 50.1 \\
\hline Oyerweight & $\mathrm{n}$ & 111 & 79 & 15 & 23 & 16 & 17 & 261 \\
\hline Overwergnt & $\%$ & 42.5 & 30.3 & 5.7 & 8.8 & 6.1 & 6.5 & 32.3 \\
\hline Ob & $\mathrm{n}$ & 12 & 14 & 2 & 4 & 3 & 0 & 35 \\
\hline Ubese & $\%$ & 34.3 & 40.0 & 5.7 & 11.4 & 8.6 & 0.0 & 4.3 \\
\hline Physical exercise & & & & & & & & \\
\hline Ye & $\mathrm{n}$ & 217 & 102 & 25 & 26 & 25 & 19 & 414 \\
\hline Yes & $\%$ & 52.4 & 24.6 & 6.0 & 6.3 & 6.0 & 4.6 & 51.2 \\
\hline No & $\mathrm{n}$ & 190 & 122 & 9 & 30 & 24 & 19 & 394 \\
\hline NO & $\%$ & 48.2 & 31.0 & 2.3 & 7.6 & 6.1 & 4.8 & 48.8 \\
\hline Taking restaurant fo & food & & & & & & & \\
\hline Yes & $\mathrm{n}$ & 257 & 124 & 14 & 29 & 25 & 26 & 475 \\
\hline & $\%$ & 54.1 & 26.1 & 2.9 & 6.1 & 5.3 & 5.5 & 58.8 \\
\hline No & $\mathrm{n}$ & 150 & 100 & 20 & 27 & 24 & 12 & 333 \\
\hline NO & $\%$ & 45.0 & 30.0 & 6.0 & 8.1 & 7.2 & 3.6 & 41.2 \\
\hline Use of can food & & & & & & & & \\
\hline Yes & $\mathrm{n}$ & 283 & 130 & 20 & 35 & 26 & 28 & 522 \\
\hline Yes & $\%$ & 54.2 & 24.9 & 3.8 & 6.7 & 5.0 & 5.4 & 64.6 \\
\hline$N o$ & $\mathrm{n}$ & 124 & 94 & 14 & 21 & 23 & 10 & 286 \\
\hline NO & $\%$ & 43.4 & 32.9 & 4.9 & 7.3 & 8.0 & 3.5 & 35.4 \\
\hline Utilization of time & & & & & & & & \\
\hline Academic & $\mathrm{n}$ & 120 & 45 & 14 & 9 & 8 & 8 & 204 \\
\hline activities & $\%$ & 58.8 & 22.1 & 6.9 & 4.4 & 3.9 & 3.9 & 25.2 \\
\hline Reading and & $\mathrm{n}$ & 100 & 42 & 0 & 12 & 13 & 5 & 172 \\
\hline watching T.V & $\%$ & 58.1 & 24.4 & 0.00 & 7.0 & 7.6 & 2.9 & 21.3 \\
\hline Games and & $\mathrm{n}$ & 27 & 21 & 0 & 2 & 5 & 1 & 56 \\
\hline sports & $\%$ & 48.2 & 37.5 & 0.00 & 3.6 & 8.9 & 1.8 & 6.9 \\
\hline
\end{tabular}




\begin{tabular}{|c|c|c|c|c|c|c|c|c|}
\hline \multirow{2}{*}{\multicolumn{2}{|c|}{ Socioeconomic variables }} & \multicolumn{6}{|c|}{ Prevalence of non-communicable diseases } & \multirow[b]{2}{*}{ Total } \\
\hline & & None & Diabetes & Problem of heart & $\begin{array}{l}\text { Diabetes and heart } \\
\text { problem }\end{array}$ & $\begin{array}{l}\text { Diabetes and kidney } \\
\text { problem }\end{array}$ & Others & \\
\hline \multirow{4}{*}{$\begin{array}{l}\text { Paper reading } \\
\text { and use mobile } \\
\text { phone } \\
\text { Use T.V. \& } \\
\text { mobile }\end{array}$} & $\mathrm{n}$ & 80 & 69 & 14 & 26 & 16 & 18 & 223 \\
\hline & $\%$ & 35.9 & 30.9 & 6.3 & 11.7 & 7.2 & 8.1 & 27.6 \\
\hline & $\mathrm{n}$ & 80 & 47 & 6 & 7 & 7 & 6 & 153 \\
\hline & $\%$ & 52.3 & 30.7 & 3.9 & 4.6 & 4.6 & 3.9 & 19.0 \\
\hline \multirow{2}{*}{ Total } & $\mathrm{n}$ & 407 & 224 & 34 & 56 & 49 & 38 & 808 \\
\hline & $\%$ & 50.4 & 27.7 & 4.2 & 6.9 & 6.1 & 4.7 & 100.0 \\
\hline
\end{tabular}

Among the investigated adults 74.4 percent were at least graduates and 26.6 percent of them were suffering from only diabetes and another 12.4 percent were diabetic patients and were also suffering from heart and kidney problem. Illiterate and primary educated adults were worst suffers from NCDs problem. The percentages of illiterate and primary educated adults were only 2.7 and 6.9 , respectively. But 38.5 percent of them were suffering from diabetes alone. Another 9 percent were diabetic patients along with heart and kidney problem. The differentials in proportions in the Level of prevalence of NCDs according to different levels of education were significant as $x^{2}=34.868$ with $\mathrm{p}$-value $=0.003$. The coefficient of association between level of education and level of prevalence of NCDs was 0.203 . The risk ratio [R.R $=1.33$ ] indicated that illiterate and primary educated adults had 33 percent more risk of affecting by any of the NCDs.

One of the reason of overweight and obesity and hence NCDs is physical inactivity [1]. Housewives, students and unemployed persons are not directly involved in physical labor [23], same fact is true for business persons, government employees and skilled workers. Only farmers and unskilled workers are directly involved in physical labor. In the light of this statement, the investigated adults of this study were divided into 4 occupational groups Viz. (i) agriculturists and unskilled labors, (ii) Business persons and skilled workers, (iii) service persons, and (iv) housewives, students and others. The number of respondents in these groups were 35,76,183 and 514, respectively. The last group was the biggest group and 29.4 percent of them were suffering from only diabetes. But another 13.8 percent were also suffering from diabetes along with heart and kidney problem. The lowest diabetic patients $(8.6 \%)$ were noted among the farmers and unskilled labors. However, a bigger group (17.1\%) of them were patients of diabetes and kidney diseases. Maximum (44.8\%) business persons and skilled labors were diabetic patients and some of them had the problem of heart and kidney. Majority (59.2) of adults of this group were facing at least one of the non-communicable diseases. With the variation in the level of occupational patterns there was significant variation in the levels of NCDs $\left[x^{2}=7023\right.$, $p$-value $\left.=0.000\right]$. The coefficient of association between level of occupation and level of NCDs was 0.283 . However, the housewives, students and others had less risk of affecting by NCDs [R.R $=0.96]$.

Majority $(58.3 \%)$ of the investigated adults were coming from rich families (monthly income Tk. 90 thousand and above) and 50.5 percent of them were suffering from at least one of the NCDs. Highest $(62.9 \%)$ NCDs affected people was observed in those families having monthly income Tk. 60-90 thousand. Least affected people was noted in lowest income group of families. Around 20 percent adults were from this group of families. Level of income and level of NCDs were significantly associated as was observed by Chisquare test $\left[x^{2}=30.241, \mathrm{p}-\right.$ value $\left.=0.011\right]$. The coefficient of association between the two afore mentioned characteristics was 0.190. However, similar risk of prevalence of NCDs was noted irrespective of highest or lower level of income of the families [0.R. = 1.09; R.R = 1.04].

Very few $(4.3 \%)$ of the adults were obese. But NCDs was prevailed among 65.7 per cent of them. Around six percent obese adults were suffering from heart diseases. With the increase in level of obesity significant increase in proportion of diabetic patients was noted as was observed by Chi-square test $\left[x^{2}=32.032, p\right.$-value $\left.=0.000\right]$. The coefficient of association between level of obesity and level of NCDs was 0.198 . The obese adults had 34 percent more risk of affecting by NCDs [R.R. = 1.34].

Among the adults 17.6 percent were smokers and 50.7 percent of them were affected by at least one of the NCDs. This corresponding percentage among non- smokers was 49.4. But there was significant association between smoking habit and level of NCDs. [ $x^{2}=13.436$, p-value $\left.=0.020\right]$. The risk ratio (1.03) indicated that the risk of prevalence of NCDs for both smokers and non-smokers was similar.

A big group (58.8\%) of respondent were habituated in taking restaurant foods. Among this group the rate of prevalence of NCDs was 0.459 . The corresponding figure among those who did not take restaurant food was 0.55 . But diabetes was more prevalent in this latter group of respondents. There was significant association between habit of taking restaurant foods and prevalence of at least one of the NCDs $\left[x^{2}=12.439, p\right.$-value $\left.=0.029\right]$. However, the risk of prevalence of any of the NCDs irrespective of taking or not taking restaurant food was almost similar [R.R $=0.84]$.

Among the adults, 64.6 percent were used to take can food including soft drinks and 45.8 percent of them were affected by at least one of the NCDs. The rate of prevalence of NCDs was higher (0.566) among the adults who did consume can food. Surprisingly enough, the prevalence of diabetes was higher among this latter group of adults. Here also significant association between habit of taking can food and prevalence of NCDs was significant $\left[x^{2}=13.381, p\right.$ - value $\left.=0.020\right]$. However, the risk of prevalence of NCDs for both groups were almost similar [R.R. $=0.77]$.

It was noted that 51.2 percent adults were used to do some 
sorts of physical exercise and 48.8 percent were not doing any physical exercise. There was no significant association between habit of doing physical exercise and prevalence of NCDs $\left[x^{2}=10.924, p\right.$ - value $\left.=0.053\right]$.

\subsection{Discriminant Analysis}

The results discussed above indicated that some of the socioeconomic variables were significantly associated with the prevalence of different types of NCD. Thus it was needed to discriminate the adults according to the diseases they were suffering. This can be done by discriminant analysis which is an advanced statistical method to discriminate the groups of observations [24] according to some pre-identified characteristic and to detect the responsible factors for discrimination.

In the present analysis, the total investigated adults were classified into 6 classes by the prevalence of different types of NCD. Some of the socioeconomic variables were significantly different for the above mentioned 6 groups of adults. This was observed by one-way analysis variance, the results of which were shown below in Table 2. These variables which were significantly different for different groups of adults were included in the discriminant analysis. The results of the discriminant function coefficients were presented in Table 3 and the results detecting the responsible variables were presented in Table 4.

Table 2. One-way analysis of variance table.

\begin{tabular}{llll}
\hline Variable & Wilk's $\Lambda$ & F & p-value \\
\hline Residence & 0.979 & 3.518 & 0.004 \\
Age & 0.917 & 14.488 & 0.000 \\
Gender & 0.987 & 2.180 & 0.054 \\
\hline
\end{tabular}

\begin{tabular}{llll}
\hline Variable & Wilk's $\Lambda$ & F & p-value \\
\hline Marital status & 0.941 & 9.982 & 0.000 \\
Religion & 0.990 & 1.586 & 0.162 \\
Education & 0.975 & 4.081 & 0.001 \\
Occupation & 0.964 & 6.028 & 0.000 \\
Income & 0.988 & 2.004 & 0.076 \\
Smoking habit & 0.983 & 2.712 & 0.019 \\
Taking restaurant food & 0.985 & 2.508 & 0.029 \\
Taking can food & 0.983 & 2.701 & 0.020 \\
Utilization of time & 0.984 & 2.661 & 0.021 \\
BMI & 0.968 & 5.223 & 0.000 \\
\hline
\end{tabular}

It was seen that gender, religion and income were not significantly different for 6 groups of adults. So, these 3 variables were not included in discriminant analysis.

As there were 6 groups of adults, 5 discriminant functions were derived. Some of the functions were significantly different from others. The results were shown below:

Table 3. Results related to test of discrimination.

\begin{tabular}{llll}
\hline Function & Wilk's $\Lambda$ & $\boldsymbol{x}^{\mathbf{2}}$ & p-value \\
\hline 1 through 5 & 0.829 & 149.703 & 0.000 \\
2 through 5 & 0.928 & 59.545 & 0.008 \\
3 through 5 & 0.976 & 19.538 & 0.722 \\
4 through 5 & 0.986 & 11.000 & 0.686 \\
5 & 0.996 & 3.267 & 0.775 \\
\hline
\end{tabular}

The first and second functions discriminated well between the groups of adults and some variables were detected responsible for discrimination. This is noted from the results of correlation coefficient (Table 5) of discriminant function sores and values of the variable.

The function 1 discriminated well from other functions and the responsible variables for this Indicated significant correlation.

Table 4. Discriminant function coefficients.

\begin{tabular}{|c|c|c|c|c|c|}
\hline \multirow{2}{*}{ Variable } & \multicolumn{5}{|c|}{ Coefficients of function } \\
\hline & 1 & 2 & 3 & 4 & 5 \\
\hline Residence & -0.220 & 0.222 & -0.169 & -0.415 & -0.375 \\
\hline Age & 0.603 & -0.290 & 0.512 & -0.400 & 0.557 \\
\hline Marital status & -0.174 & -0.402 & 0.189 & 0.297 & 0.871 \\
\hline Education & -0.181 & -0.050 & 0.520 & 0.158 & 0.267 \\
\hline Occupation & 0.090 & 0.722 & 0.272 & -0.405 & 0.167 \\
\hline Smoking habit & -0.154 & 0.284 & -0.177 & 0.006 & 0.063 \\
\hline Taking restaurant food & 0.064 & 0.081 & 0.651 & 0.202 & -0.253 \\
\hline Taking can food & 0.061 & 0.365 & -0.173 & 0.599 & -0.169 \\
\hline Utilization of time & 0.109 & 0.186 & -0.585 & 0.227 & 0.353 \\
\hline BMI & 0.294 & 0.271 & -0.070 & 0.250 & 0.327 \\
\hline
\end{tabular}

Table 5. Correlation coefficients of variables with discriminant function scores.

\begin{tabular}{llllc}
\hline \multirow{2}{*}{ Variable } & \multicolumn{4}{c}{ Correlation coefficients of variable with discriminant function scores for different functions } \\
\cline { 2 - 5 } & $\mathbf{1}$ & $\mathbf{2}$ & $\mathbf{3}$ & $\mathbf{4}$ \\
\hline Residence & -0.333 & 0.362 & -0.014 & -0.429 \\
Age & $0.864^{*}$ & -0.053 & 0.131 & -0.192 \\
Marital status & $-0.713^{*}$ & 0.018 & 0.078 & 0.290 \\
Education & -0.436 & 0.070 & $0.441^{*}$ & 0.192 \\
Occupation & -0.304 & $0.693^{*}$ & 0.175 & -0.007 \\
Smoking habit & -0.172 & $0.509^{*}$ & -0.013 & -0.305 \\
Taking restaurant food & 0.250 & 0.248 & $0.558^{*}$ & -0.080 \\
Taking can food & 0.209 & 0.369 & 0.021 & $0.507^{*}$ \\
Utilization of time & 0.304 & 0.219 & $-0.477^{*}$ & $0.659^{*}$ \\
BMI & $0.485^{*}$ & 0.275 & 0.028 & -0.312 \\
\hline
\end{tabular}


Discrimination were age marital status and BMI and the most responsible one was age. The second function discriminated well from other functions and the most important variables for this discrimination were occupation and smoking habit and most important one was occupation. The third function discriminated well from other functions and the important variables for this discrimination were education, habit of taking restaurant food and utilization of time and the variable utilization of time was the most responsible one for this discrimination. The fourth function discriminated well and the responsible variables for this discrimination were residence, habit of taking restaurant and can food. The fifth function did not discriminate well and no responsible variable was detected.

\section{Discussion}

The analytical results presented above were derived from the analysis of data collected from 808 adults of Bangladesh. Among the investigated adults 75.2 percent were from urban areas and 53.6 percent of them were suffering from at least one of the non-communicable diseases as against the 49.6 percent patients in the sample. The urban adults were worst sufferer $(53.6 \%)$ from the problem and diabetes was predominant $(45.4 \%)$ among them. A smaller proportion $(26.5 \%)$ of rural adults were diabetic and there was significant difference in the prevalence of NCDs among both urban and rural adults. The urban adults had 43 percent more risk of affecting by NCDs compared to rural adults. This result was similar as was reported earlier in different studies $[4,25]$. Among the adults 51.1 percent were currently married and the prevalence of different types of noncommunicable diseases among them was higher (60.1\%). Currently married adults were more exposed to different types of NCDs. Similar finding was reported earlier in another study [25].

Age, education, occupation are the risk factors for overweight and obesity and hence these are the influencing variables for enhancing the levels of NCDs. This fact was reported in both home and abroad [12-19, 26-27]. The present study also provided the similar information. Old age (50 years and above) adults were more exposed to the prevalence of different types of non-communicable diseases. Illiterate and primary educated adults had more risk of affecting by NCDs. Physical inactivity is another risk factor for NCDs. This characteristic is related to occupation. Skilled workers (like machine operator, bus /truck driver), housewives and students, service persons [24, 29] are, by nature of work, not involved in physical activity directly and they have more risk of overweight and obesity and hence of NCDs. This indicated that business persons and skilled workers had higher risk of prevalence of NCDs.

It was well documented, in home and abroad, that overweight and obese people had the higher risk of [12-19, 26-29] diabetes which is a dominant component of NCDs. This study also provided the same evidence that overweight and obese adults were at higher risk prevalence of NCDs.

Restaurant and junk food containing more sugar, salt, saturated fats and involvement in sedentary activities [1-2] are the risk factors for NCDs. From the present analysis it was noted that there was significant association between levels of NCDs and taking restaurant food and can food. Significant association was also noted between the levels of NCDs and the utilization of time by the adults. Those who killed their maximum time in reading paper and/ or watching T.V. or using mobile phone for longer time, they were more exposed to NCDs.

The discriminant analysis indicated that the investigated adults classified into 6 classes according to the prevalence of different types of NCDs were significantly different. The analysis detected the variables age, marital status, body mass index, occupation, smoking habit, utilization of time and habit of taking restaurant food responsible for the discrimination of adults by the different levels of noncommunicable diseases.

\section{Conclusion}

The non-communicable diseases are the major health hazard in both developed and developing countries [30]. The major sources of NCDs are overweight and obesity, tobacco use, physical inactivity, unhealthy diets including junk foods and drinks [31]. The major incidence and outcome of NCDs, is diabetes resulting cardiovascular diseases, chronic kidney disease, hypertension, etc. In the present analysis the prevalence of NCDs was noted among 49.4 percent investigated adults. The adults were classified into six classes. One group of 407 adults were free of any of NCDs. Among the remaining 401 adults 27.7 percent were diabetic patients, 4.2 percent were patients of heart problem, 6.9 percent were suffering from diabetes and heart problem, 6.1 percent suffering from diabetes and kidney diseases and another 4.7 percent were patients of different types of other diseases. The target of the analysis was to discriminate these 6 groups of adults and to detect the variables responsible for discrimination. The findings indicated that these 6 group of adults were significantly different and difference were noted due to the variables mainly age, marital status, level of BMI, occupation and smoking habit. The other responsible variables for discrimination were food habit and utilization of time.

The results indicated that the NCDs cannot be avoided but its prevalence can be controlled by implementing some rules and regulations congenial for the better health management of the public. The following aspects can be considered and action can be taken accordingly.

(i) people are to be encouraged for detection, screening, and treatment of NCDs,

(ii) people are to be encouraged to avoid smoking, unhealthy foods and junk foods. They should take home made food as per possible,

(iii) people are to be encouraged to take more fruits and 
vegetables and fewer foods high in sugar, salts and saturated fats,

(iv) people should be advised to take more water instead of sugary drinks,

(v) People are to be suggested to limit watching television and to limit the use of smart phone,

(vi) people are to be motivated to be engaged in some sort of physical labor as and when they get chance,

(vii) Urban people can walk to their nearby working place and they should develop a habit of morning and/or evening walk,

The health authority can play a decisive role to implement the above proposals. The community can do a lot in achieving the target of reducing the prevalence of NCDs.

\section{References}

[1] United Nations (2014): Non-communicable diseases Deemed Development Challenge of Epidemic Proportions in Political Declaration adopted during Landmark General Assembly Summit, United Nations, Department of public Health.

[2] WHO: Fact sheets / detail / obesity-and-overweight (2018); February, 2018, http//www.who.int /news-room.

[3] WHO (2005): Preventing chronic Diseases a Vital Investment, Cataloging-in-Publication Data, World Health Organization, 2005.

[4] Md. Mortuza, A.; Bhuyan, K. C. and Fardus, F. (2018): A study on identification of socioeconomic variables associated with no-communicable diseases among Bangladeshi adults, AASCIT, 4 (3), 24-29; http://www.aascit.org.journal/ajbse.

[5] Karar, Z. A.; Alam, N.; Streatfield, P. K. (2009): Epidemiological transition in rural Bangladesh, Global Health Action 19, 2. doi: 10.3402/gha.V2io,1904.

[6] Zhang, Q. L.; Rothenbacher, D. (2008): Prevalence of kidney disease in population-based studies: Systematic review, BMC Public Health 8, 117. doi: 10.1186/1471-2458-8-117.

[7] WHO (2018): Chronic Respiratory Diseases, World Health Organization, Retrieved 2018-10-31.

[8] WHO (2018): About Chronic Respiratory diseases, World Health Organization, Retrieved 2018-10-31.

[9] WHO (2007): Impact of tobacco related illness in Banglades, New Delhi, World Health Organization.

[10] International Diabetes Federation (2011): Country estimates table, IDF diabetes atlas, $6^{\text {th }}$ edition.

[11] Saquib, N.; Saquib, J.; Ahmed, T,; Khanam, M. A.; Cullen, M. R. (2012): Cardiovascular diseases and type II diabetes in Bangladesh: a systematic review ant meta- analysis of studies between 1995-2010, BMC Public Health, 12, 434.

[12] Bhuyan, K. C.; Ahmed, Md. M. and Fardus, J. (2017): Socioeconomic factors associated with overweight an obesity: A case study among adult people of Bangladesh, AJSE, 16 (2), 119-124.

[13] Bhuyan, K. C.; Fardus, J. and Khanam, M. (2016): Discriminating the students of universities by their smoking habit, AJSE, 15 (1).

[14] Bhuyan, K. C. and Fardus, J. (2019): Level of obesity and socioeconomic factors of a group of adult people of Bangladesh: A factor analysis approach, Amer, Jour. Data Mining and Knowledge Discovery, 4 (1), 8-14, doi: 10.11648/j.ajdmkd.20190401.12.

[15] Fardus, J. and Bhuyan, K. C. (2016): Discriminating diabetic patients of some rural and urban areas of Bangladesh: A discriminant analysis approach, Euromediterrean Bio. Jour. 11 (9), 134-140.

[16] Skliros, E. A.; Markoures, P. Sotiropoulas, A.; et al (2008): The relationship between body mass index and hypertension in elderly Greeks: the Nemea Primary Care Study. Jour. Amer. Geriatric Soc. 56 (5), 379-385.

[17] Bertino, B.; Ardiri, A. M.; Ali, F. T, Boemi, P. M.; Cilio, D. et al (2006): Obesity and related diseases: an epidemiological study in Eastern Sicily, Minerva Gastroenterol Dietol, 5 (40), 379-385.

[18] Calamusa, G.; Amodio, E.; Costantino, C.; Maria, D. Pasquate.; Gelsomino, V.; Morici, M.; Palmeri, A.; Termini, S.; Firenze, A.; Massenti, F. M. and Vitale, F. (2012): Body mass index and factors associated with overweight and obesity: a cross-sectional study of adult subjects living in a small city of Western Sicily (Italy), Italian Jour. Pub. Health, 9 (3), e7539. doi: 10.2427/7539.

[19] Besen- Engquist, K. and Chang, M. (2011): Obesity and cancer risk: recent review and evidence, Currr. Onclo Rep. 13 (1), $71-76$.

[20] Mokdad, A. H.; Ford, E. S.; Bowman, B. A.; Dietz, W. H.; Vinicor, F.; Bales, V. S. et al (2003): Prevalence of obesity, diabetes, and obesity-related health risk factors 2001, JAMA, 289, 76-79.

[21] Akter, S.; Rahaman, M. M.; Sarah, K. A.; and Sultan, P. (2014): Prevalence of diabetes and pre-diabetes and their risk factors among Bangladeshi adults: A Nationwide survey, Bulletin of the WHO, 92, 204-213 A.

[22] Paymane, A. and Miranda, P. (2018): Images of measurements of obesity, BMJ, $360 . \quad$ doi: https//doi.org/10.1136/methodbmj.k.1274.

[23] Syed, M. S.; Debra, N.; Muhammad, H. R.; Musa, R. and Gul, N. (2004): Assessing obesity and overweight in a high mountain Pakistani population, Tropical Medicine and International Health, 9 (4), 526-532.

[24] Bhuyan, K. C (2019): A note on the application of discriminant analysis in medical research, Archives of Diabetes and Obesity, 2 (2), 142-146.

[25] Bhuyan, K. C.; Mortuza MD, A. and Jannatul, F. (2018): Discriminating patients suffering from non-communicable diseases: A case study among Bangladeshi adults, Biomed. J. Sci. \& Tech. 10 (1), DOI: 10.26717/BJSRR.2018.10.001898.

[26] Rabi, D. M.; Edwards, A. L.; Southern, D. A,; Svension, L. W.; Sargious, P. N.; Norton, P; Larsen, E. T. and Ghali, W. A. (2006): Association of socioeconomic status and risk of diabetes related mortality with diabetes prevalence and utilization diabetes care services, BMC Public Health Services Research, 6, 124. 
[27] Hussain, A; Rahim, M. A.; Azad, Khan, A. K.; Ali, S. M.; Vaater, S. (2005): Type II diabetes in rural and urban population: diverse prevalence and associated risk factors in Bangladesh, Diabet Med, 22, 931-936.

[28] Andy, K. (2019): The majority of truk drivers are obese and smoke, Business Insider, CDC. Niosh and Federal Motor Carrier Safety Administration.

[29] Ramchandran, A; Snehalata, C.; Shetty, A. S. and Nandita, A. (2012): Trends in prevalence of diabetes in Asian countries, World Diabetes, 3 (66), 110-117.
[30] Prakashchandra, R. D. and Naido, D. P. (2016): Glycemic control profile in diabetes patients: A sub-analysis of the phoenix lifestyle project. Euromediterranean Biomedical Journal, 11 (05), 33-39.

[31] Pamel, A. J. and Jennifer, W. (2018): Introduction: Noncommunicable diseases prevention policies in six African countries. 